\title{
Audição e exposição ao tolueno - uma contribuição para o tema
}

\author{
Audition and exhibition to toluene - a contribution for the theme
}

\author{
Lívia Sanches Calvi Augusto', Luiz Alexandre Kulay², Eloisa Sartori Franco ${ }^{3}$.
}

1) Mestrado. Fonoaudióloga Clínica e Ocupacional. Mestre em Gestão Integrada em Saúde do Trabalho e Meio Ambiente - Centro Universitário SENAC.

2) Doutorado. Engenheiro Químico. Doutor em Engenharia Química - Escola Politécnica da Universidade de São Paulo (EPUSP). Pesquisador do Grupo de Prevenção da Poluição - GP2 do Departamento de Engenharia Química - EPUSP.

3) Doutorado. Fonoaudióloga. Doutora em "Saúde da Criança e do Adolescente" - Departamento de Pediatria - FCM/UNICAMP; Docente do Curso de Fonoaudiologia da Universidade Metodista de Piracicaba - UNIMEP.

Instituição: Centro Universitário SENAC - Campus Santo Amaro.

Campinas / SP - Brasil.

Endereço par correspondência: Lívia Sanches Calvi Augusto - Rua Olavo Bilac, 419 Apto. 71 - Cambui - Campinas/SP - Brasil - CEP: $13024-110$ - Telefone: (+55 13) xxxx-xxxx - E-mail: bioaudio@gmail.com.br ou luiz.akulay@sp.senac.brou eloisafranco@uol.com.br

Artigo recebido em 11 de Agosto de 2010. Artigo aprovado em 5 de Fevereiro de 2011.

\section{RESUMO}

Introdução: Com os avanços tecnológicos e as mudanças nos processos produtivos, os trabalhadores estão expostos a diferentes agentes físicos e químicos em seu ambiente laboral. O tolueno é um solvente orgânico presente em colas, tintas, óleos, dentre outros.

Objetivo: Comparar os achados literários que evidenciam que trabalhadores expostos simultaneamente a ruído e solventes têm maior probabilidade de desenvolverem uma perda auditiva de origem periférica.

Método: Revisão de literatura a respeito da perda auditiva ocupacional em trabalhadores expostos a ruído e tolueno. Resultados: A exposição isolada ao tolueno também pode desencadear uma alteração dos limiares auditivos. Estes achados audiométricos, por ototoxicidade a exposição ao tolueno, apresentam audiogramas semelhantes ao por exposição ao ruído, o que torna dificultoso diferenciar um resultado audiométrico de exposição combinada - ruído e tolueno - e exposição apenas ao ruído.

Conclusão: A maioria dos estudos foi projetado para gerar hipóteses e deveria ser considerado como passos preliminares de uma pesquisa adicional. Até hoje os agentes no ambiente de trabalho e seus efeitos têm sido estudados de maneira isolada e os limites de tolerância destes, não consideram as exposições combinadas. Considerando que os trabalhadores estão expostos a múltiplos agentes e que a perda auditiva é irreversível, os testes implementados devem ser mais completos e todos os trabalhadores devem fazer parte do programa de prevenção auditiva, mesmo expostos a baixas doses do limite de exposição recomendado.

Palavras-chave: ruído ocupacional, tolueno, perda auditiva provocada por ruído, trabalhadores.

\section{SUMMARY}

Introduction: With the technological advances and the changes in the productive processes, the workers are displayed the different physical and chemical agents in its labor environment. The toluene is solvent an organic gift in glues, inks, oils, amongst others.

Objective: To compare solvent the literary findings that evidence that diligent displayed simultaneously the noise and they have greater probability to develop an auditory loss of peripheral origin.

Method: Revision of literature regarding the occupational auditory loss in displayed workers the noise and toluene.

Results: The isolated exposition to the toluene also can unchain an alteration of the auditory thresholds. These audiometric findings, for ototoxicity the exposition to the toluene, present similar audiograms to the one for exposition to the noise, what it becomes difficult to differentiate a audiometric result of agreed exposition - noise and toluene - and exposition only to the noise.

Conclusion: The majority of the studies was projected to generate hypotheses and would have to be considered as preliminary steps of an additional research. Until today the agents in the environment of work and its effect they have been studied in isolated way and the limits of tolerance of these, do not consider the agreed expositions. Considering that the workers are displayed the multiples agent and that the auditory loss is irreversible, the implemented tests must be more complete and all the workers must be part of the program of auditory prevention exactly displayed the low doses of the recommended limit of exposition.

Keywords: noise, occupational, toluene, hearing loss, noiseinduced, workers. 


\section{INTRODUÇÃO}

Com os avanços tecnológicos e as mudanças nos processos produtivos, os trabalhadores estão expostos cotidianamente a diferentes agentes físicos e químicos em seu ambiente laboral, os quais - em um numero significante de situações - acabam por ser reverter em risco à saúde. Esse quadro apresenta-se ainda mais insegura quando a prevalência desses riscos volta-se a exposição combinada desses produtos ao ruído.

Nasúltimas décadas, as perdas auditivas ocupacionais têm sido discutidas nas publicações científicas, constituindo um problema de saúde importante em nossa sociedade. Entretanto, surgem estudos sobre outros agentes, além da presença do ruído nos ambientes de trabalho de inúmeros processos produtivos, que combinados, representam um risco potencial à audição (1).

Dentre os principais compostos químicos ototóxicos, pode-se destacar os metais, os asfixiantes e os solventes, considerando este último grupo, o mais presente nos meios industriais. O tolueno é um solvente orgânico presente em colas, tintas, óleos, dentre outros, e sua avaliação no ambiente laboral dá-se através de seu bioindicador urinário (exame de ácido hipúrico) (2).

Neste artigo, nos deteremos a apresentar estudos do efeito combinado entre ruído e tolueno, no intuito de ampliarmos os conhecimentos quanto ao efeito da exposição concomitante entre esse solvente e o ruído.

\section{REVISÃO DA LITERATURA}

A exposição humana ao tolueno ocorre a partir do uso ocupacional, no ambiente doméstico, através da inalação com fins de abuso e da exposição ambiental. A maior fonte de exposição ambiental ao tolueno é a produção e uso da gasolina. Grandes quantidades de tolueno são introduzidas no ambiente anualmente através do uso da gasolina e da produção e processos de refinamento de petróleo. Calcular os níveis de exposição humana provenientes do ar, do solo e da água pode ser difícil (3).

Nasúltimas décadas, as perdas auditivas ocupacionais têm sido discutidas ostensivamente no meio acadêmico pelo fato, indiscutível, de constituírem-se em um problema de saúde importante na nossa sociedade moderna. No entanto, estudos mais recentes revelam que a presença de agentes químicos, emassociaçãoao ruído fazem potencializar a perda de audição no ambiente de trabalho (1).

Os efeitos adversos de solventes orgânicos na saúde foram descritos em muitos estudos $(4,5,6)$. A baixas ou moderadas concentrações em ar, os solventes orgânicos podem causar sintomas passageiros como euforia, dor de cabeça, e vertigem $(7,8)$ enquanto que, em níveis mais elevados podem conduzir a anestesia, problemas cardiovasculares e doenças das vias respiratórias (6). A exposição de longo prazo pode ainda causar danos para o Sistema Nervoso Central como Déficits Cognitivos e Emocionais, o que prejudicaria uma boa prática do trabalhador em seu ambiente ocupacional, mesmo que em tarefas simples (9).

O tolueno é um hidrocarboneto aromático, líquido e incolor, com odor característico, derivado do alcatrão da hulha e do petróleo, utilizado como solvente para tintas, na produção de explosivos, corantes, medicamentos e detergentes e como solvente industrial para borrachas e óleos e ainda na produção de outros químicos (10). É largamente utilizado na indústria gráfica. É um dos componentes da cola de sapateiro e da gasolina. Esta última corresponde a principal fonte de emissão atmosférica e exposição da população em geral.

O Tolueno é um solvente empregado de forma ampla em processos de transformação antropica, particularmente como solvente. Nesta condição, o referido produto químico aromático pode, dado o grau de volatilidade em condições padrão de temperatura e pressão $-25^{\circ} \mathrm{C}$ e $1 \mathrm{~atm}$ - aportar maiores impactos ao ser humano, manifestados na forma de irritação da pele e da mucosa. Os efeitos agudos do tolueno são semelhantes aqueles decorrentes da intoxicação etanólica, propiciando um quadro de estimulação seguido de depressão do Sistema Nervoso Central (SNC). Já em situação de exposição crônica os riscos são de hepatotoxicidade, nefrotoxicidade e perda auditiva ( 5 , 11).

Os mecanismos de ação das substâncias ototóxicas causam prejuízos funcionais ou danos celulares na orelha interna, principalmente nas estruturas finais da audição e equilíbrio, agindo primeiramente ao nível do tronco cerebral ou nas vias auditivas centrais (12).

Quando se trata da perda auditiva propriamente dita, as características da curva audiométrica de um paciente acometido de exposição exclusiva a ruído ou de outro, com diagnóstico confirmado de ototoxicidade são bastante semelhantes. Isso porque ambos os quadros são de origem neurosensorial, denotam lesões cocleares, tendem a ser irreversíveis, acometem inicialmente altas frequências (sons agudos) e quase sempre são bilaterais (2).

O efeito ototóxico dos agentes químicos - e dentre estes, dos solventes orgânicos - tem se configurado em tema de investigação de grande número de pesquisadores. 
A NIOSH identificou a emergente necessidade de estabelecer limites seguros para exposição combinada de substâncias químicas e ruído (13). Consta da Diretiva Europeia 2003/10/EC que estabelece exigências de segurança mínima na saúde de trabalhadores expostos a riscos, que o empregador deverá dar atenção particular para trabalhadores expostos simultaneamente a agentes químicos e ruído, ao levar em conta a avaliação de risco (14).

A ponte mais significativa da literatura disponível sobre os efeitos do Tolueno no Sistema Auditivo advêm essencialmente de duas origens: casos em que os pacientes inalaram voluntariamente o solvente (15) e de experimentos laboratoriais conduzidos com animais. Estes estudos evidenciam que a exposição a altas concentrações de Tolueno, pela diferentes vias de administração (oral, inalação ou subcutânea) acentuama perda auditiva. De maneira complementar a essa tese, nos estudos realizados em animais, foi possível notar grande sinergismo entre este solvente e a exposição ao ruído.

Tal conclusão é corroborada por evidências experimentais com animais, em que a inalação a altos níveis de tolueno prejudica o sistema auditivo e causam perda dos limiares audíveis.

\section{DISCUSSÃO}

Com o crescimento da produtividade e o avanço da tecnologia, os riscos de acidentes e doenças de origem ocupacional aumentaram e deram origem a vários efeitos nocivos à qualidade de vida, à segurança individual e coletiva do trabalhador.

Em um estudo com 151 trabalhadores do setor de rotogravuras de uma indústria gráfica de São Paulo, expostos simultaneamente a ruído (85-94dB) e tolueno (78-390 ppm), investigou-se o efeito combinado da exposição simultânea a ambos os agentes sobre a audição e o equilíbrio (16).

Neste estudo, usando-se de testes de audição e equilibrio, os trabalhadores foram divididos em três grupos: expostos a ruído e tolueno, expostos só a ruído e sem nenhuma exposição. Nos resultados encontrados, a porcentagem da perda auditiva observada no grupo exposto aos dois agentes foi significativamente maior do que nos outros dois grupos.

Alémdisso, as medidasdoreflexodo músculo estapédio sugeriram que as perdas auditivas encontradas neste grupo eram significativamente diferentes das do grupo exposto a ruído, sobretudo no que se refere a provável localização da lesão. Mais uma vezaqui, a porcentagem de falhas na triagem de equilíbrio foi significativamente maior no grupo de trabalhadores expostos a ambos os agentes.

Ainda na mesma linha de pesquisa, outro estudo conduziu uma investigação com solventes orgânicos e ruído, observando seus efeitos ocupacionais. Os indivíduos pesquisados eram todos trabalhadores de indústria de rotogravura, do sexo masculino, com mais de um ano de empresa (17).

Como mecanismo de coleta de dados foram utilizados o exame audiométrico e imitanciometria, além de questionário (idade, tempo de trabalho, tempo de exposição a ruído e produtos químicos, diabetes, hipertensão, infecção de ouvido, uso de medicamentos ototóxicos, atividades de lazer com ruído, serviço militar).

Os trabalhadores foram divididos em quatro grupos: 50 trabalhadores sem qualquer tipo de exposição, 50 trabalhadores com exposição só a ruído (88-97dB), 51 trabalhadores expostos a ruído (88-98 dB) e tolueno (100 ppm) e 39 trabalhadores expostos a mistura de diferentes solventes (o maior componente dessas misturas era o tolueno).

Os resultados mostraram prevalência de maior perda auditiva no grupo com exposição simultânea a ruído e tolueno (53\% no grupo com exposição a ruído e tolueno, 8\% no grupo sem exposição, 26\% no grupo com exposição somente a ruído e 18\% no grupo com exposição a mistura de diferentes solventes). Nos resultados dos exames de Imitanciometria, encontrou-se presença de recrutamento, principalmente nos grupos de trabalhadores expostos a ruído e a ruído e tolueno.

No ano de 1993, um outro estudo investigou trabalhadores expostos a uma concentração média de 97ppm de solventes, que apresentaram latências absolutas e interpicos maiores nas ondas nos intervalos I-III-V no PEATE em relação aos não expostos. Com estes dados, sugeriu-se que as alterações ocasionadas pelo tolueno possam se localizar na região do tronco encefálico e vias auditivas centrais. Todos os indivíduos deste estudo tinham audiometria normais e ausência de sintomas relacionados a exposição a solventes (18).

Em um outro estudo com solventes e ruído dentro dos limites exigidos, em uma empresa produtora de embalagens com aproximadamente 800 funcionários, os resultados apresentados não mostraram potencialização de efeitos. Ocorrência de perdas auditivas em trabalhadores expostos apenas a solventes chamaram a atenção sobretudo e trabalhadores jovens e com menos tempo de exposição. Nesta pesquisa utilizou-se dos exames de audiometria e imitanciometria, e os colaboradores foram separados e três grupos: exposição somente ao ruído, exposição somente aos solventes e exposição combinada (19). 
Em experimentos com animais, usou-se diversos pares de solventes e a incidência das interações de ototóxicos não aditivos. Foram utilizados ratos machos da raça Long Evans em locais onde doses de solventes (10\% de concentração) eram administrados por 5 dias das 8:30 as 16:30 horas de Segunda a Sexta-feira. Os efeitos eram comparados de 2 a 13 dias após a exposição e a função auditiva era obtida na semana seguinte da exposição usando BERA (resposta de potencial evocado no cérebro). Os solventes utilizados foram tricloroetileno (TCE), tolueno (TOL), xilenos mistos (XYL) e clorobenzenos (CBZ) e a combinação foi TOL+TCE, XYL+TCE, XYL+CBZ, CBZ+TOL (20).

Por resultados estes autores obtiveram evidências de que a combinação de modo dose-aditivo dos solventes ototóxicos nos efeitos da audição dos ratos. No estudo com CBZ+TOL os efeitos desenvolveram ao longo da semana e não imediatamente. O limiar do grupo exposto foi de $10 \mathrm{~dB}$ maior do que no grupo de controle.

Segundo os autores, mesmo com os resultados obtidos, não se pode concluir que os solventes sempre se combinarão aditivamente em seus efeitos na audição, pois obtém-se sinergismo quando o efeito tóxico das exposições combinadas é maior do que a soma dos efeitos observados.

Em um estudo com ratos com longa exposição ao tolueno por inalação apresentaram achados sugestivos de lesões no sistema vestibular central sem evidências de lesões na função vestibular periférica (21).

Com o objetivo de estudar o efeito do tolueno na estrutura e função do Sistema Auditivo, aplico-se testes de potencial evocado (BERA - avaliação da cóclea) em ratos adultos do sexo masculino, de peso médio variável entre 450-500g, e criados em laboratório. O experimento teve inicio quando a prole atingiu o limite de 200 dias de vida, durando por um intervalo variável compreendido entre 3 e 4 meses. Completado o sexto mês de idade os animais foram confinados em caixas individuais, condição de isolamento na qual foram mantidos pelos 30 dias que precederam o inicio do processo experimental (22).

Após serem sedados receberem eletrodos capazes de medir seus potenciais evocados os ratos foram submetidos a dosagens variáveis de vapores de tolueno com concentrações, respectivamente de 1000, 1250, 1500, 1750 e 2000 ppm, por um período regular de 6 hs diárias, durante cinco dias da semana, ao longo de 4 meses.

Os resultados obtidos indicaram que apenas três das dosagens de tolueno a que foram submetidos os animais de $1500 \mathrm{ppm}$, de $1750 \mathrm{ppm}$ e de $2000 \mathrm{ppm}$ - produziram alteração confirmada de limiar auditivo. A exposição ao tolueno resultou em déficit auditivo significativo na amplitude da média frequência $(8-24 \mathrm{KHz})$ dos ratos adultos. O resultado obtido mostrou uma alteração coclear, pela inalação do tolueno e o principal achado foi o trauma coclear localizado no meio do órgão de Corti (16-20 KHz) e do meio para o ápice (4-5 KHz).

Outros autores pesquisaram os efeitos da exposição simultânea do tolueno (2000 ppm) e do ruído (92 dB) em ratos. Estes animais foram expostos ao tolueno durante $6 \mathrm{~h} /$ dia, 5 dias da semana, pelo período de um mês. Os resultados mostraram a indução de perda auditiva, células ciliadas externas prejudicadas e estereocília danificada, com maior predominância nos ratos expostos simultaneamente ao ruído e a o tolueno. O dano coclear induzido pelo tolueno ou por ruído foi causado por dois mecanismos diferentes, envenenamento e mecânico (23).

Com todas as informações e resultados científicos existentes até então, novas pesquisas mostraram novamente os efeitos ocupacionais da exposição de trabalhadores a solventes e ruído de uma indústria de rotogravuras, acrescentando o cálculo da concentração dessas misturas no ar e o exame de ácido hipúrico. Participaram do estudo 124 trabalhadores com exposição a mistura de solventes (principalmente tolueno, etanol e ethyl acetate) e diferentes níveis de ruído. Realizou-se um questionário com todos os trabalhadores (histórico de trabalho, aspectos psicosociais, medicamentos, saúde em geral, exposição a ruído e produtos químicos), exame de audiometria e imitanciometria. Colheu-se também a urina destes funcionários pós jornada de trabalho, para exame de ácido hipúrico (24).

Os resultados da audiometria apontaram 49\% dos trabalhadores com perda auditiva bilateral e os resultados de imitanciometria sugeriram transtorno auditivo central ou retrococlear na maioria dos trabalhadores. Os resultados mostraram também alteração do exame de ácido hipúrico em 95\% dos trabalhadores. Com isto, sugeriu-se piora da perda auditiva, quando o trabalhador está também exposto ao tolueno (a partir dos dados de ácido hipúrico) e 4 vezes mais chances de perda auditiva em trabalhadores com exposição a tolueno e ruído. A concentração de tolueno no ar não apresentou relação significativa com a perda auditiva dos trabalhadores e com os resultados de ácido hipúrico.

$\mathrm{Na}$ avaliação de 64 ratos expostos a tolueno e etanol, dividiu-se os animais em 3 grupos com exposição e um grupo de controle. O primeiro grupo estava exposto a vapores de tolueno ( $1750 \mathrm{ppm}, 6$ horas por dia, 5 dias da semana por 4 meses). O segundo grupo ficou exposto ao etanol $(4 \mathrm{~g} / \mathrm{kg}$ por 4 meses), o qual foi injetado via intubação gástrica e depois exposto em ar ambiente por 6 horas; e o terceiro grupo foi exposto simultaneamente ao 
tolueno e ao etanol (o etanol era injetado antes da exposição ao tolueno). Realizou-se exame de ácido hipúrico nos animais expostos ao tolueno. A urina foi coletada no $1^{\circ}$ dia e depois a cada 4 dias. Nenhum alimento ou bebida foi dado aos animais durante a exposição (25).

Os resultados mostraram que a perda auditiva é mais frequente na exposição a tolueno e etanol do que só a tolueno. O etanol puro modifica o metabolismo do tolueno. Não se constatou perda auditiva na exposição isolada ao etanol.

Avaliou-se também a cóclea de ratos expostos a tolueno, a partir do exame de Eletrococleografia. O estudo foi desenvolvido utilizando-se dois grupos cada qual com 8 ratos adultos. O primeiro grupo ficou exposto a vapores de tolueno (1750 ppm) durante $6 \mathrm{~h}$ por dia, 5 dias da semana, por 4 meses e o segundo não tinha exposição (26).

Após esse período de exposição, realizou-se o exame de Eletrococleografia e os resultados mostraram alteração de células auditivas localizadas na porção de frequências médias-baixas da cóclea e não só em frequências médias. Assim as células perdidas da Cóclea, concentravam-se na região de frequências médias baixas e sugeriu-se relação de perda auditiva com a exposição ao tolueno.

Em um outro estudo com emissões otoacústicas evocadas transitórias (EOAET) e o efeito de supressão, observou-se um grupo exposto a ruído e tolueno, comparando com um grupo somente exposto ao ruído e a um outro sem exposição. Foram avaliados 140 colaboradores com idade entre 18-48 anos com resultados normais de audiometria e imitanciometria (27).

A prevalência de ausência de respostas nas EOAET em pelo menos uma das orelhas foi maior no grupo exposto a ruído e tolueno (64\%) e no grupo exposto apenas a ruído (62\%), que no grupo não exposto (27,5\%).

A prevalência de ausência do efeito de supressão no grupo exposto a ruído e tolueno foi maior $(48,9 \%) \mathrm{em}$ relação aos expostos a ruído $(17,4 \%)$ e não expostos (7.5\%).

O risco de ausência de supressão no grupo ruído e tolueno foi expressivamente maior quando comparado aos outros grupos. Os resultados sugerem a existência de uma ação neurotóxica do tolueno sobre a audição afetando particularmente a porção retrococlear da via auditiva e ocasionando um tipo de lesão distinta daquela provocada pelo ruído.

Em pesquisa sobre o efeito do ruído e de mistura de solventes aferidas por meio de audiometria de altas frequências, observou-se limiares piores na comparação dos limiares auditivos nas altas frequências do grupo exposto simultaneamente a ruído e mistura de solventes. Esta diferença foi significante para as altas frequências, enquanto que os resultados dos limiares testados em audiometria convencional não mostraram diferenças significativas (28).

Pesquisou-se também alterações na Avaliação do Processamento Auditivo Central em um grupo de trabalhadores expostos a mistura de solventes. Participaram do estudo 10 trabalhadores expostos a mistura de solventes e 10 trabalhadores não expostos, com resultados de audiometria e imitanciometria dentro dos padrões de normalidade (29).

Os achados do processamento auditivo central foram mais baixos no grupo exposto a mistura de solventes, sugerindo que, mesmo sem apresentar alteração no exame auditivo, trabalhadores expostos a mistura de solventes apresentam dificuldades com as questões cotidianas, o que foi comprovado com as alterações auditivas centrais apresentadas no teste de processamento.

Na avaliação do risco de perda auditiva em trabalhadores de uma indústria de adesivos expostos a ruído e tolueno, dividiu-se os trabalhadores em 3 grupos: no primeiro grupo, 58 trabalhadores foram expostos a ruído (78.6$87.1 \mathrm{~dB}$ ) e tolueno (33,0 ppm, 107,6 ppm e 164,6 ppm); no segundo grupo, 58 trabalhadores expostos somente a ruído (67.9 - 72,6dB); e no terceiro grupo, 60 trabalhadores do setor administrativo, que não tinha qualquer tipo de exposição, servindo de grupo de controle (30).

Todos responderam a um questionário com informações de saúde e estilo de vida e realizaram exame audiométrico. Os testes foram realizados 14 horas depois do término da jornada. A porcentagem da perda auditiva foi calculada a partir do resultado da orelha pior. O grupo exposto a ruído e tolueno foi subdividido em outros grupos, levando em consideração o nível do ruído. Aproximadamente $28 \%$ dos trabalhadores expostos a ruído e tolueno trabalhavam há mais e 20 anos. A predominância das concentrações de ruído foram: setor ruído e tolueno: 83,9dB; setor ruído 85,0 dB e 70,0 no setor administrativo. Apenas 15\% dos trabalhadores expostos a ruído utilizavam EPI. A prevalência da perda auditiva foi muito maior no grupo de ruído e tolueno $(86,2 \%)$ em relação ao grupo exposto só ao ruído (44,8\%) e 5\% no grupo administrativo.

Em pesquisa com exposições a tintas e ruído, estudou-se setores de pintura de automóveis de duas empresas e verificou efeito agravante da exposição a tintas sobre os limiares auditivos de indivíduos expostos a ruído entre 81 e $85 \mathrm{~dB}$. As perdas auditivas verificadas no grupo exposto a ruído e tintas foi semelhante as observadas no grupo exposto somente a ruído entre 92-107dB (31). 
$\mathrm{Na}$ avaliação dos efeitos da exposição a ruído e solventes sobre as vias auditivas periféricas e central em trabalhadores de uma indústria gráfica de Guarulhos no período de setembro/2004 a agosto/2005, observou-se a associação da exposição de 3 solventes orgânicos (gasolina, n-hexano e tinner) e a alteração na via auditiva central foi verificada por meio do resultado do teste do potencial evocado auditivo de longa latência P300 (PEAL-P300) (32).

A pesquisa foi realizada com 136 trabalhadores e a prevalência de perdas auditivas encontradas no grupo exposto a ruído e solventes (23,3\%) foi consideravelmente maior que nos outros 2 grupos, não expostos (8\%), somente expostos a ruído (12,5\%), expostos somente a solventes (20\%).

Os resultados do estudo sugerem que a exposição ao ruído teve maior repercussão sobre o limiar auditivo e a exposição aos solventes mostrou forte associação com alterações nos resultados do PEALL-P300.

Estudos como os descritos antes, em sua maioria realizados com animais criados em laboratórios, mostram os efeitos da exposição combinada ou não ao ruído e solventes (neste caso, o tolueno) e os diferentes métodos de avaliação do sistema auditivo.

Todas as análises de associação realizadas indicaram que as exposições, combinadas ou não, associam-se a casos de perdas auditivas. Os resultados sugeriram que a exposição a altas concentrações de misturas de solventes e ao tolueno num ambiente ruidoso, podem aumentar significativamente o risco de adquiriruma perda auditiva ocupacional. Os resultados da imitanciometria também sugeriram alteração do sistema auditivo central.

Os testes de audiometria e imitanciometria utilizados nos estudos não são suficientes para avaliar os efeitos de solventes à audição. Os outros métodos de avaliação utilizados, nos mostram a importância de uma bateria completa de exames audiológicos para determinação do local e tipo de lesão.

Estes outros testes mostraram que os solventes ototóxicos danificam as células ciliadas da cóclea, sugerindo que o tolueno pode danificar seletivamente membranas celulares. As células ciliadas externas, que facilitam a codificação da informação auditiva pelo processo motor da cóclea, foram os alvos mais frequentes dos ototóxicos.

Não se pode concluir, no entanto, que os solventes sempre se combinarão aditivamente em seus efeitos na audição. A infinidade de produtos e as diferentes concentrações impedem uma avaliação confiável de seus efeitos.
Os traumas induzidos por solventes não seriam causados pela contaminação do fluido, mas por intoxicação do tecido envolvendo o sulco externo, em vez do nervo auditivo (20, 33).

Os resultados sugeriram também a existência de uma ação neurotóxica do tolueno sobre a audição afetando particularmente a porção retrococlear da via auditiva e ocasionando um tipo de lesão distinta daquela provocada pelo ruído. O registro das EOAET e a análise do efeito de supressão podem servir com instrumento importante na detecção precoce das alterações auditivas de origem coclear e retrococlear e para a elaboração de ações preventivas em audiologia nos ambientes de trabalho (27).

Na Tabela 1, encontra-se a descrição dos principais artigos descritos acima, de forma resumida, sobre a mistura de solventes e ruído.

\section{COMENTÁRIOS FINAIS}

Até hoje os agentes no ambiente de trabalho e seus efeitos têm sido estudados de maneira isolada e os limites de tolerância destes, não consideram as exposições combinadas. Considerando que os trabalhadores estão expostos a múltiplos agentes e que a perda auditiva é irreversível, os testes implementados devem ser mais completos e todos os trabalhadores devem fazer parte do programa de prevenção auditiva, mesmo expostos a baixas doses do limite de exposição recomendado. Estudos sobre os efeitos ototóxicos do tolueno na exposição ocupacional ainda não são conclusivos.

É importante lembrar que, como para o ruído, a simples presença do agente ototóxico estudado (no caso o tolueno), não é sinônimo de exposição. Para que ocorra algum tipo de efeito no órgão auditivo, a dose absorvida, que depende, entre outros, dos níveis de concentrações no ambiente e do tempo de exposição, deve ser suficiente para causar o efeito

Sendo assim, é importante que os gestores e/ou profissionais que trabalham com a questão da Saúde do Trabalhador, sejam alertados do efeito combinado acerca da exposição a ruído e substâncias químicas, para que se possa buscar ferramentas para discussões de normas vigentes e dos programas de conservação auditiva, contribuindo para uma melhor gestão na saúde do trabalhador. A perspectiva de estudo dos efeitos combinados, não só do tolueno, mas da maioria dos agentes químicos, deve merecer maior atenção para que se possa planejar medidas adequadas de proteção, repensando os Programas de Conservação Auditiva existentes. 


\begin{tabular}{|c|c|c|c|c|c|c|}
\hline 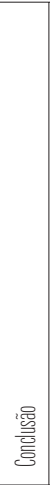 & 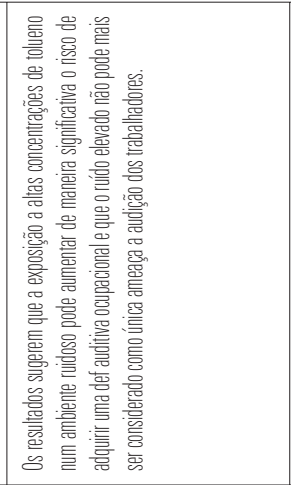 & 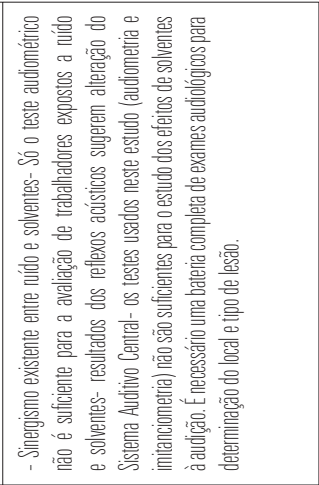 & 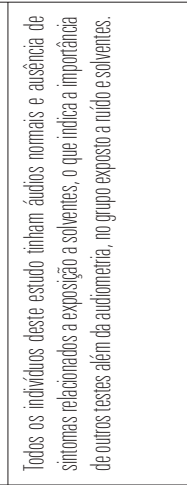 & 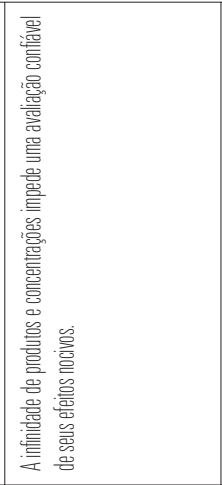 & 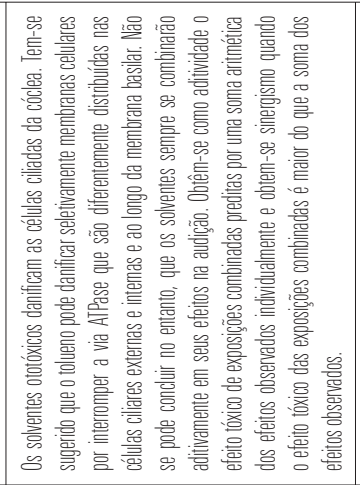 & 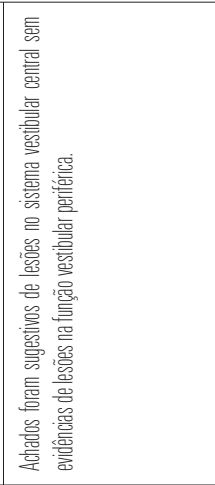 \\
\hline 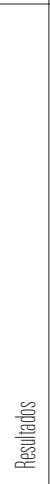 & 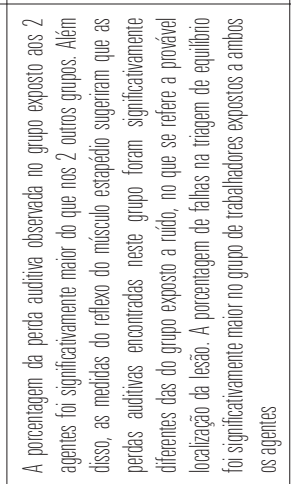 & 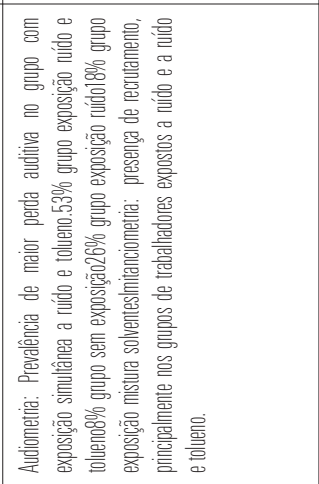 & 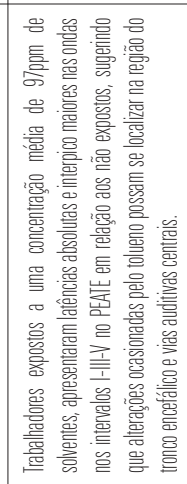 & 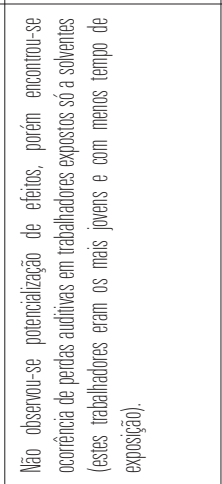 & 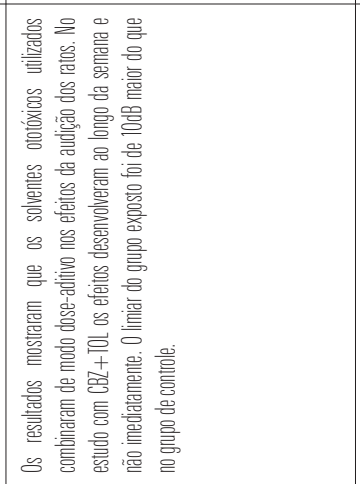 & \\
\hline 善 & 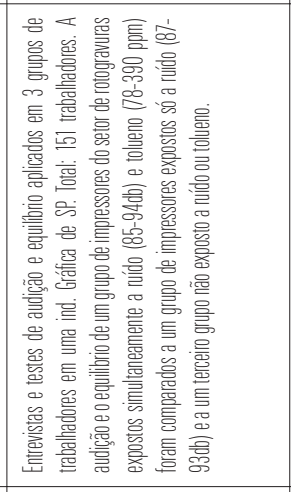 & 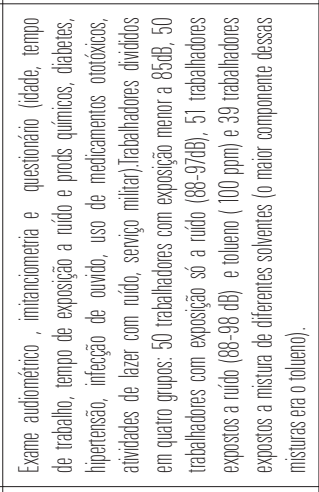 & 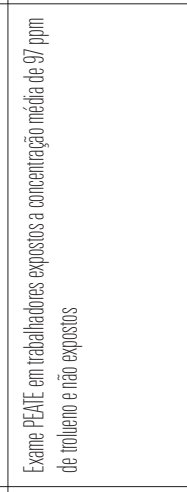 & 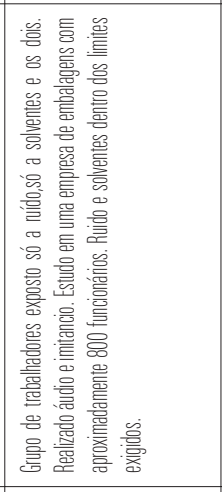 & 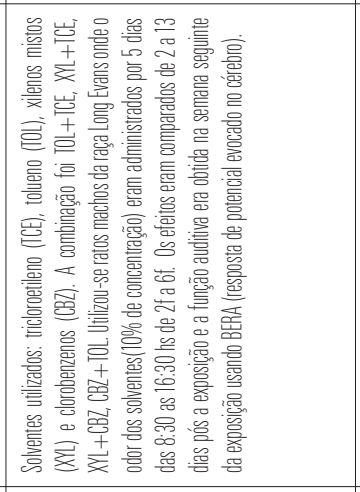 & 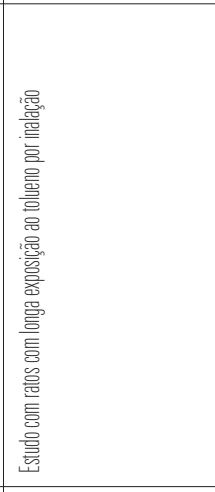 \\
\hline 䜌 & 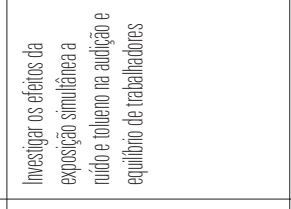 & 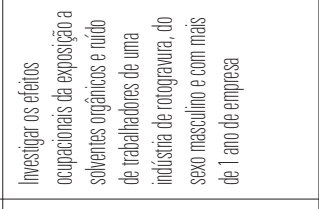 & 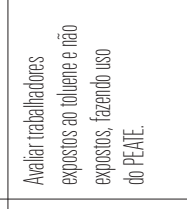 & 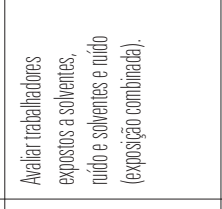 & 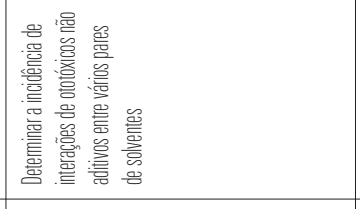 & 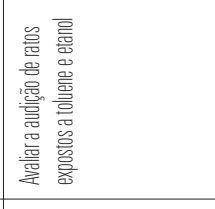 \\
\hline 噈 & 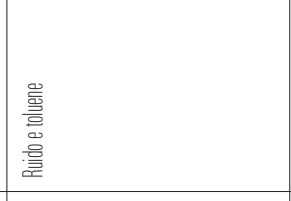 & 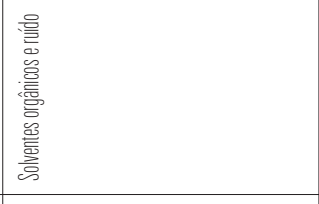 & \begin{tabular}{|l} 
彦 \\
峷
\end{tabular} & 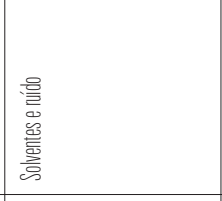 & 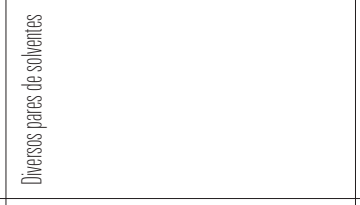 & 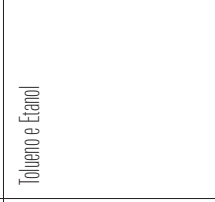 \\
\hline 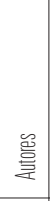 & 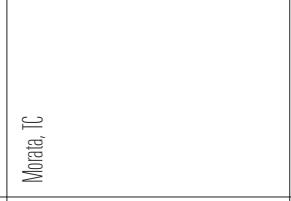 & 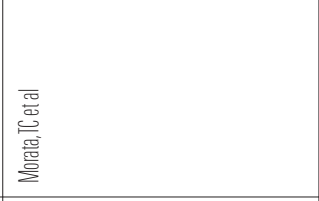 & 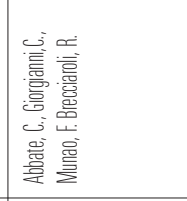 & 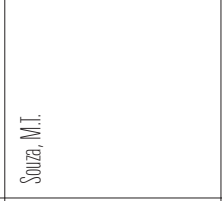 & 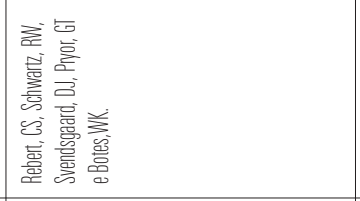 & 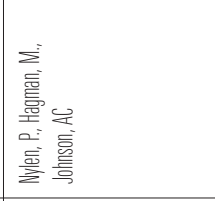 \\
\hline 畺 & 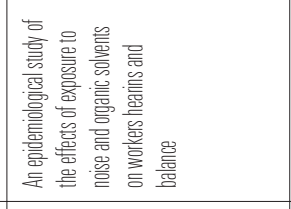 & 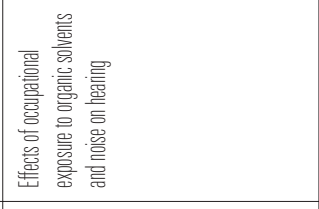 & 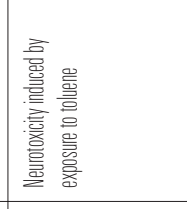 & 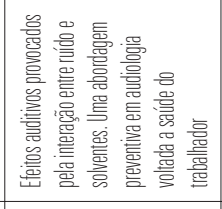 & 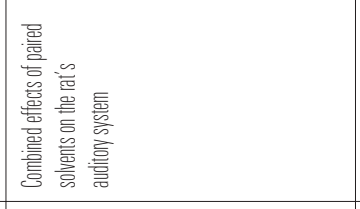 & 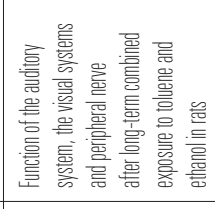 \\
\hline 울 & 骂 & 吕 & 艿 & 骂 & 嘿 & 岁 \\
\hline
\end{tabular}




\begin{tabular}{|c|c|c|c|c|}
\hline 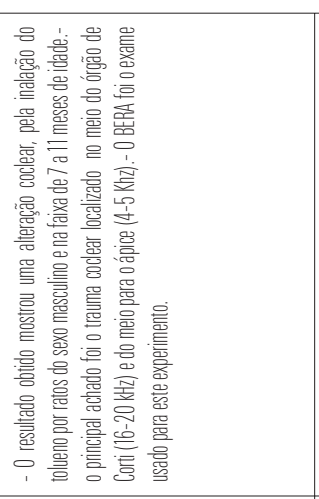 & 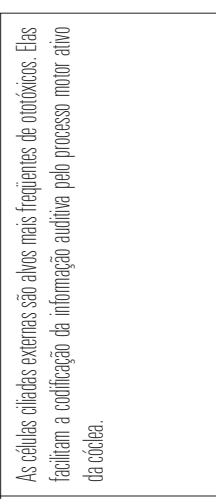 & 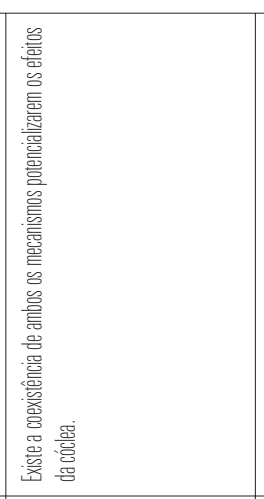 & 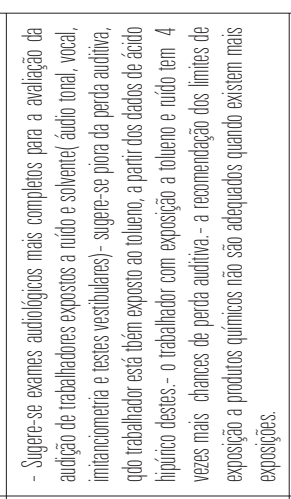 & 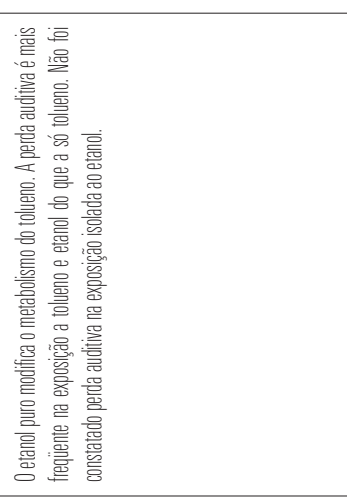 \\
\hline 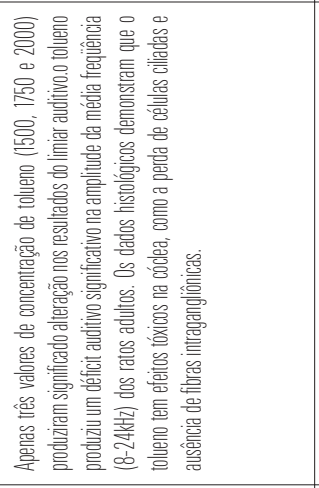 & 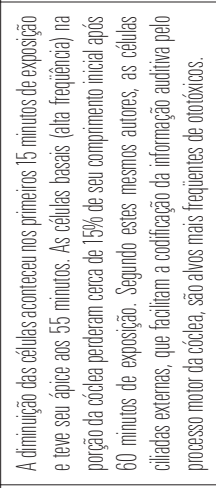 & 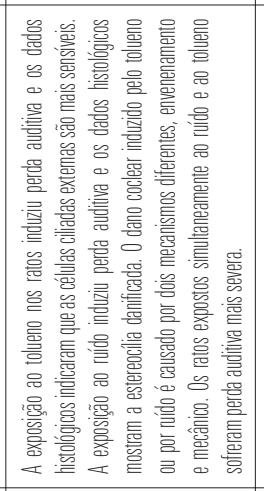 & 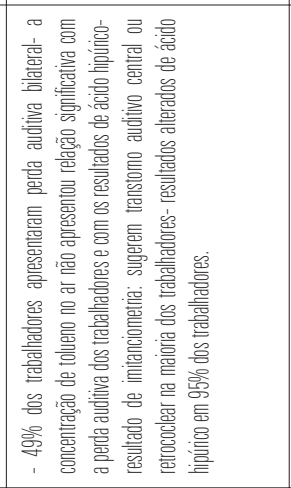 & \\
\hline 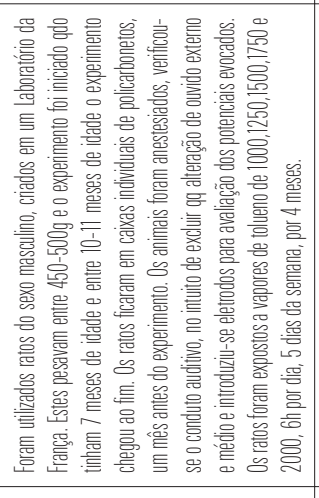 & 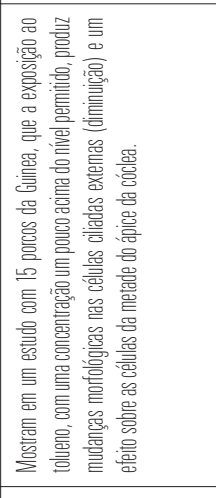 & 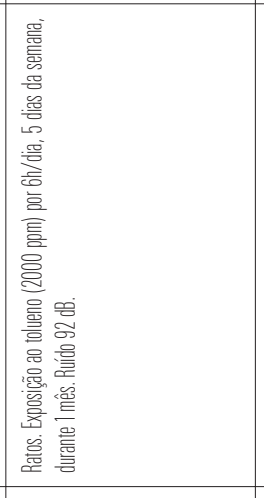 & 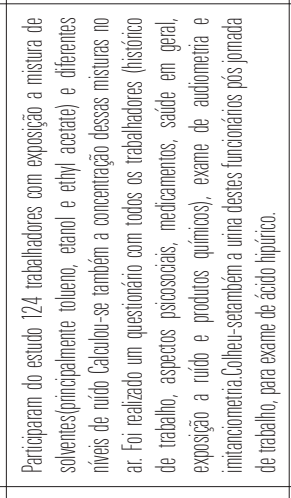 & 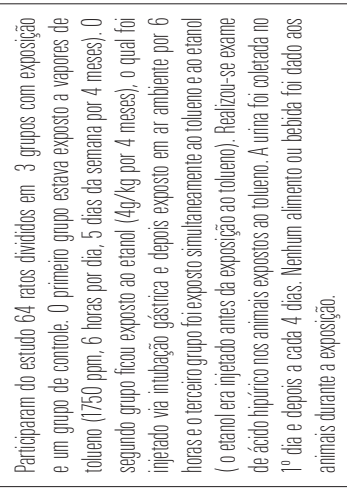 \\
\hline 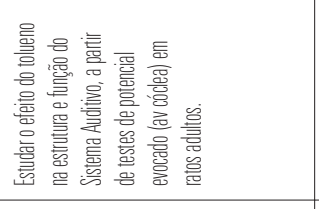 & 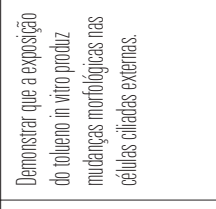 & 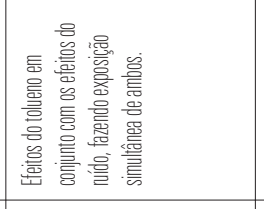 & 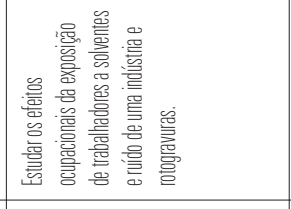 & 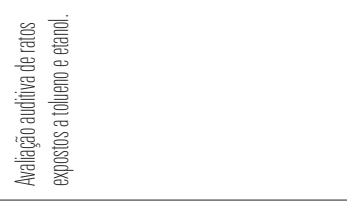 \\
\hline 哭 & 䯺 & 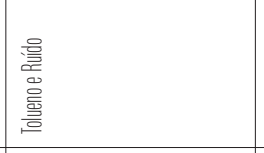 & 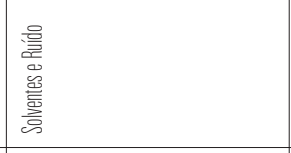 & 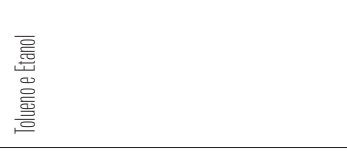 \\
\hline 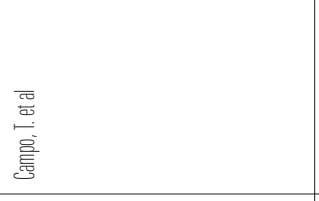 & 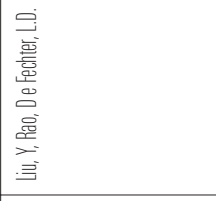 & 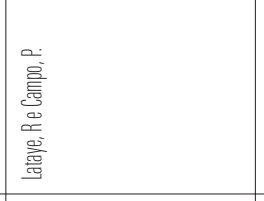 & 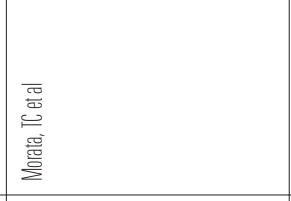 & 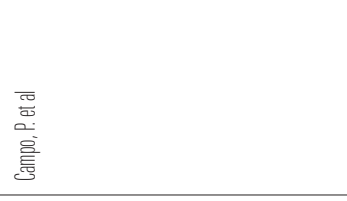 \\
\hline 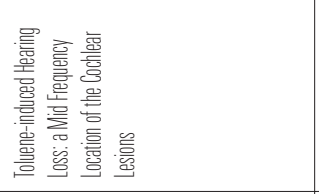 & 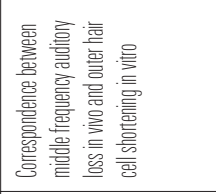 & 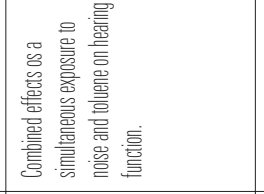 & 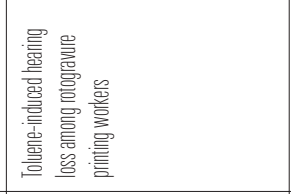 & 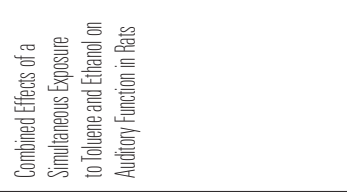 \\
\hline 骂 & 骂 & 埡 & 离 & 骂 \\
\hline
\end{tabular}




\begin{tabular}{|c|c|c|}
\hline 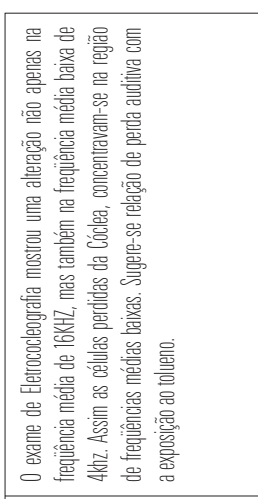 & 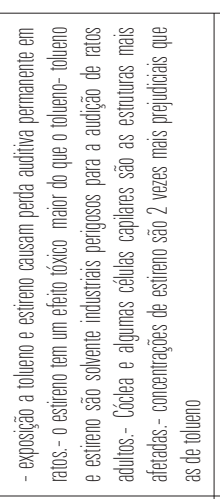 & 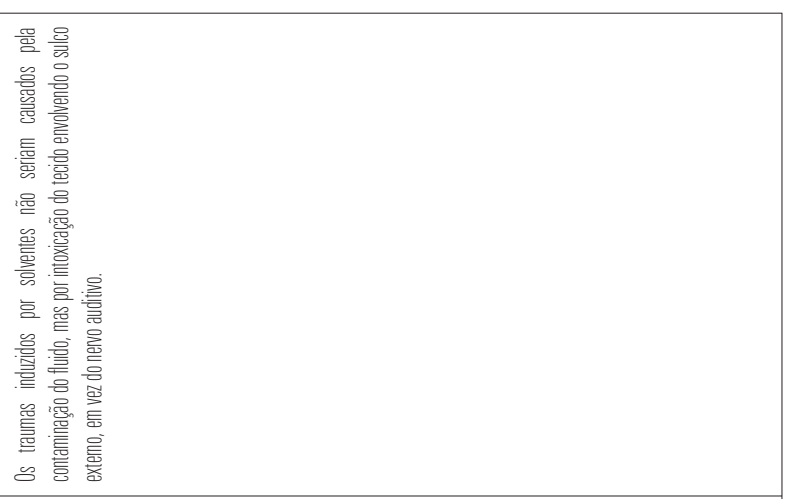 \\
\hline 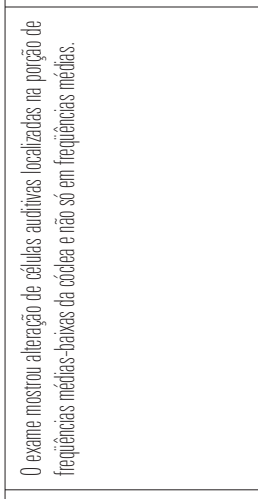 & 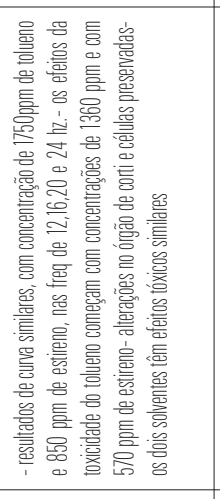 & 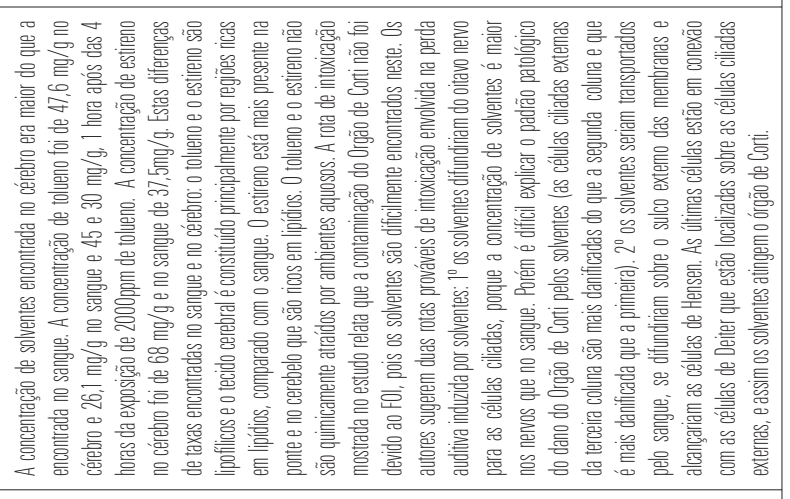 \\
\hline 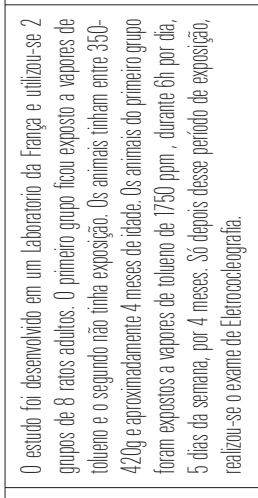 & 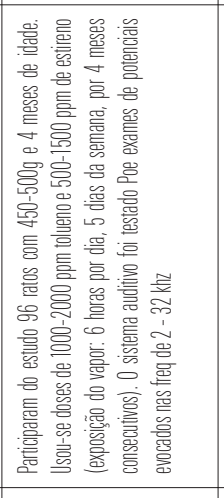 & 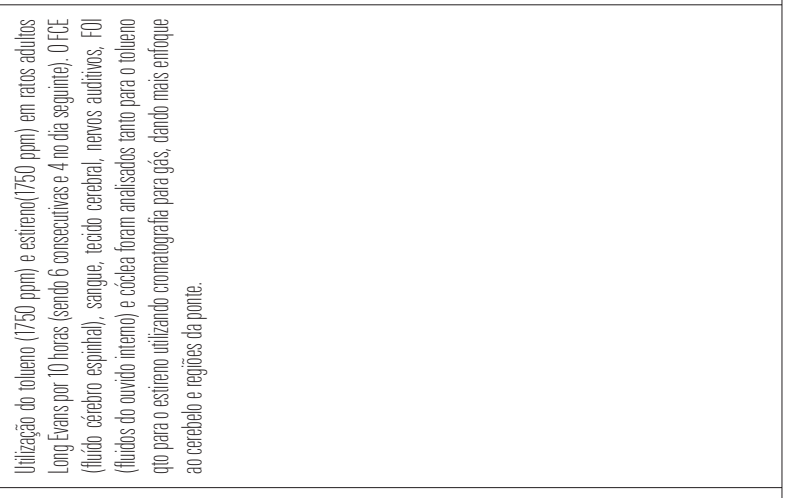 \\
\hline 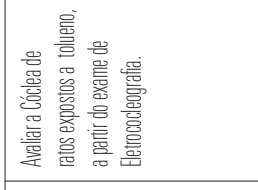 & 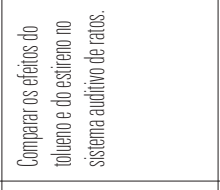 & 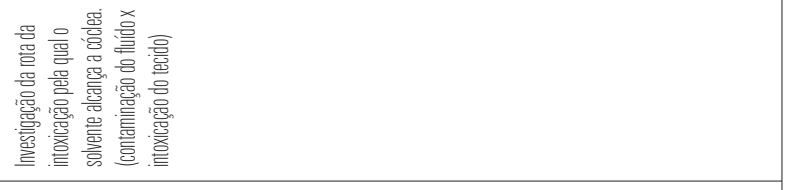 \\
\hline & & 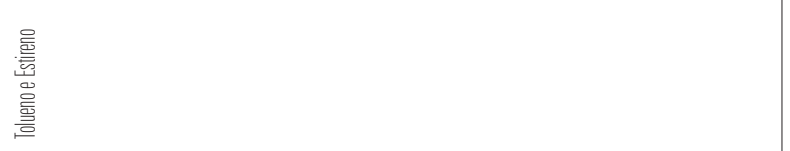 \\
\hline 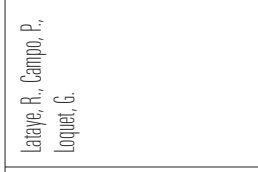 & 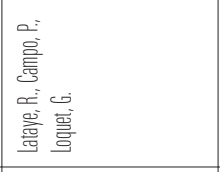 & 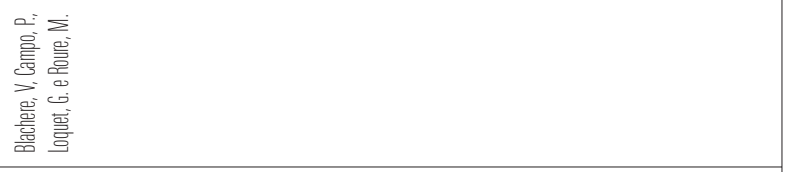 \\
\hline 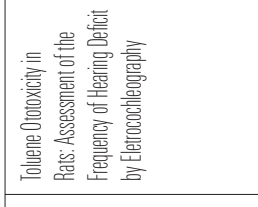 & 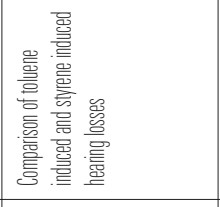 & 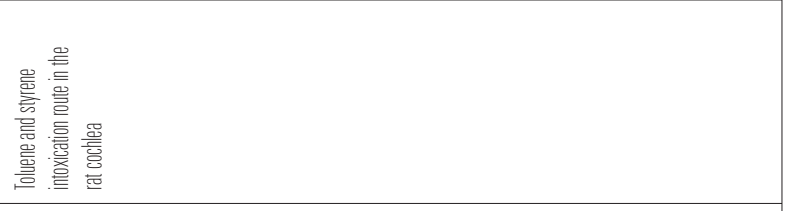 \\
\hline$g$ & 兽 & 黫 \\
\hline
\end{tabular}




\begin{tabular}{|c|c|c|c|c|c|c|}
\hline 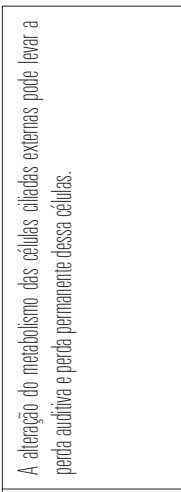 & 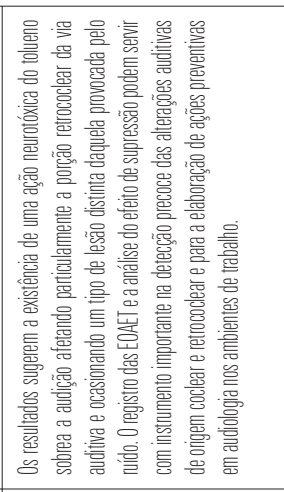 & & 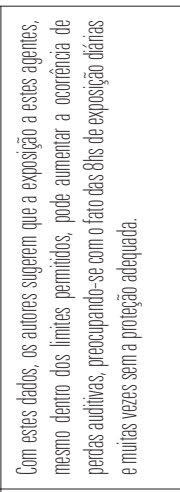 & 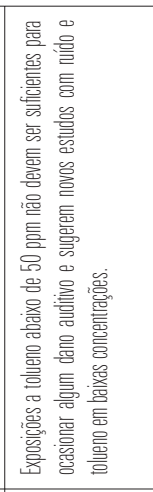 & 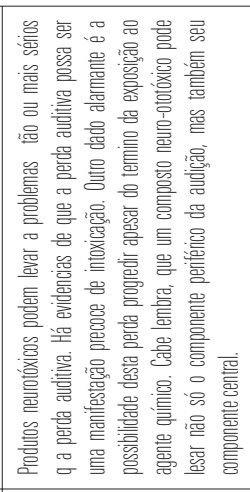 & 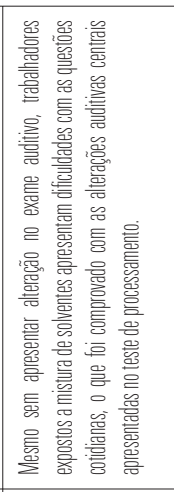 \\
\hline 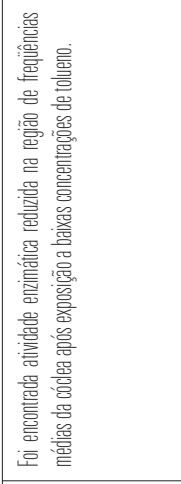 & 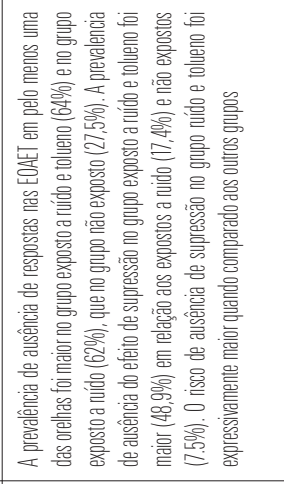 & 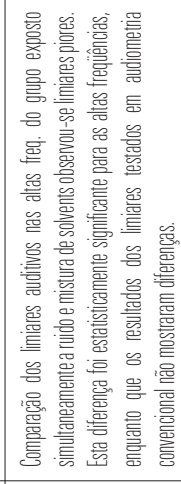 & 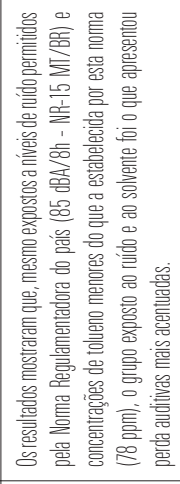 & 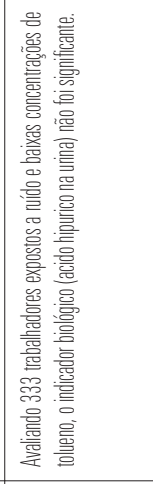 & 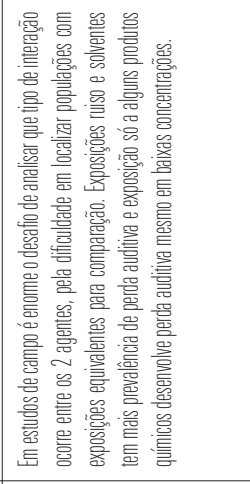 & 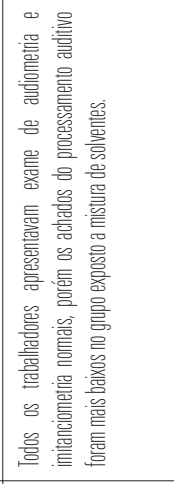 \\
\hline 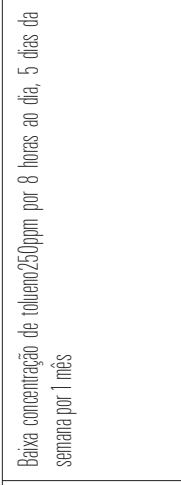 & 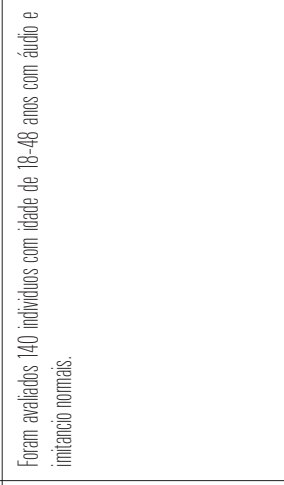 & & 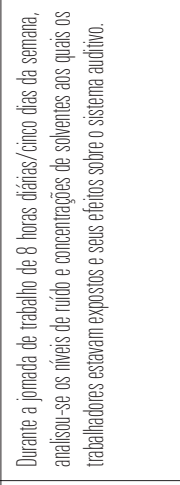 & & & 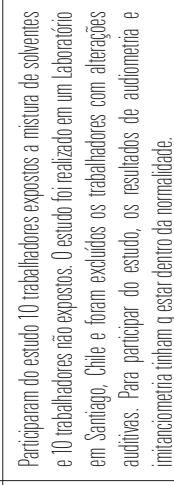 \\
\hline 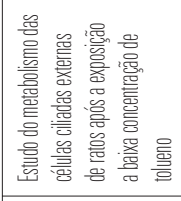 & 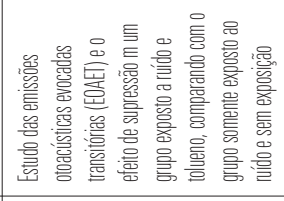 & 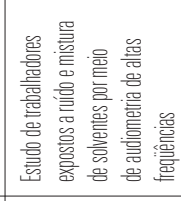 & 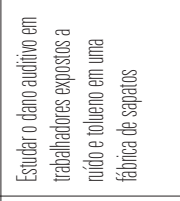 & & 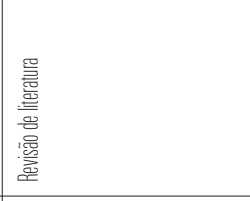 & 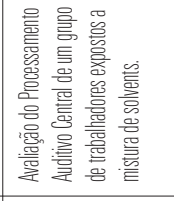 \\
\hline 餢 & 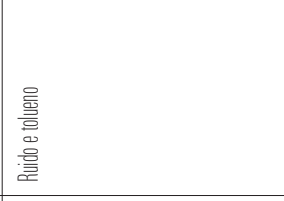 & 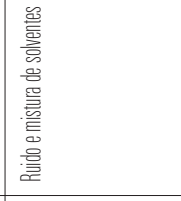 & 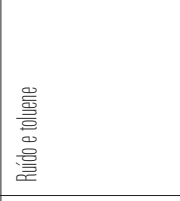 & 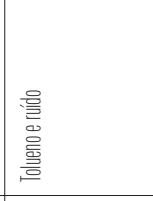 & 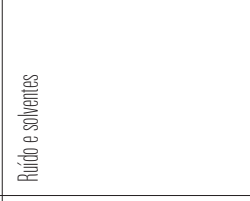 & 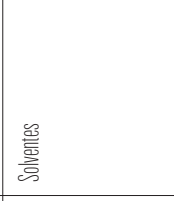 \\
\hline 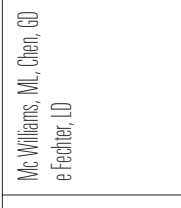 & 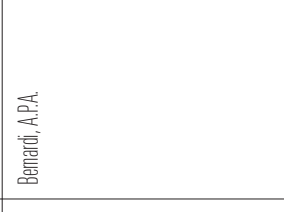 & 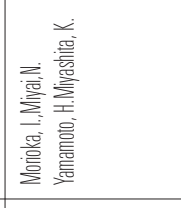 & 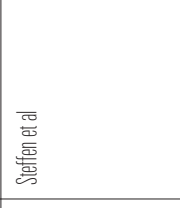 & 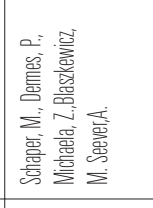 & 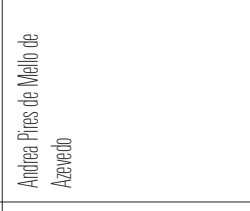 & 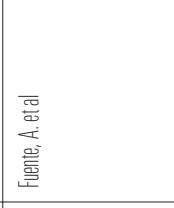 \\
\hline 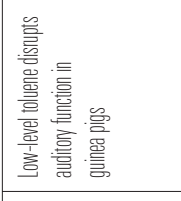 & 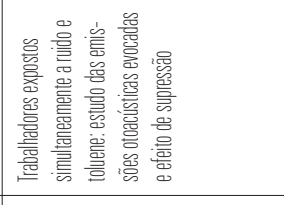 & 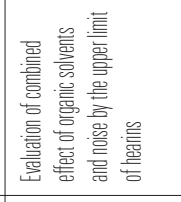 & 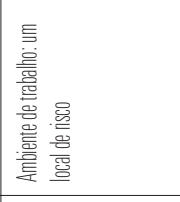 & 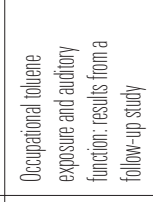 & 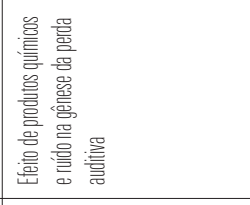 & 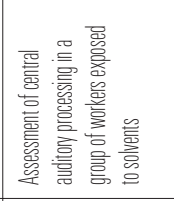 \\
\hline ర్ & 总 & 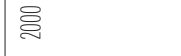 & శ్రి & 兽 & 䓌 & 兽 \\
\hline
\end{tabular}




\begin{tabular}{|c|c|c|c|}
\hline 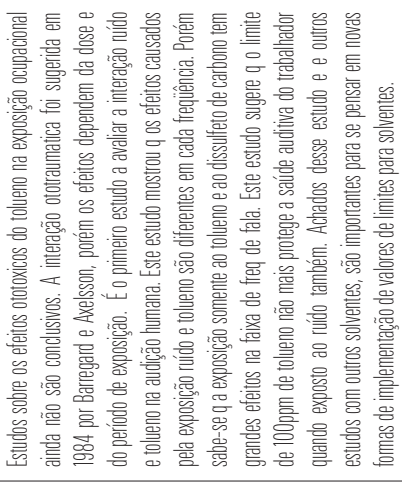 & & 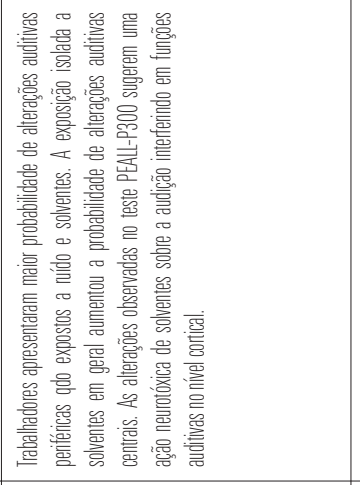 & 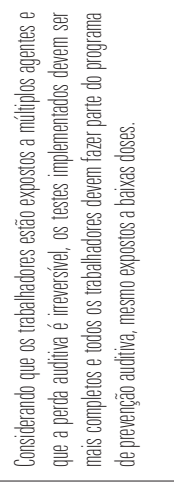 \\
\hline 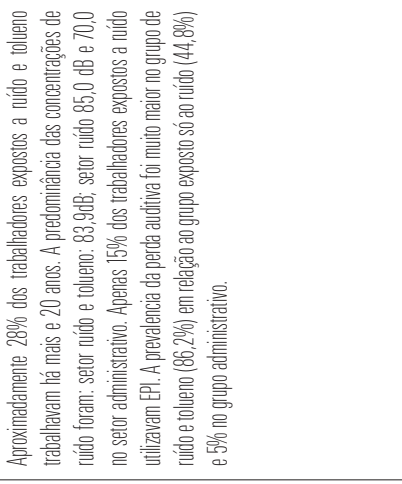 & 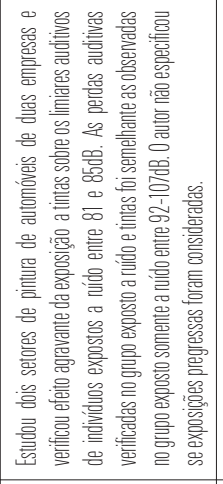 & 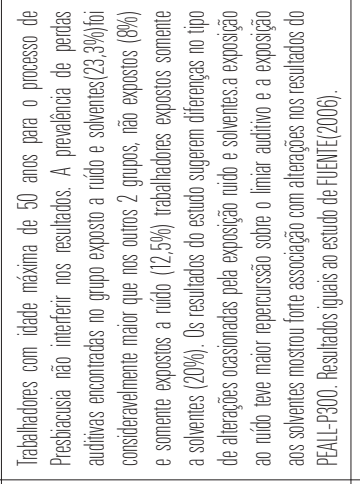 & 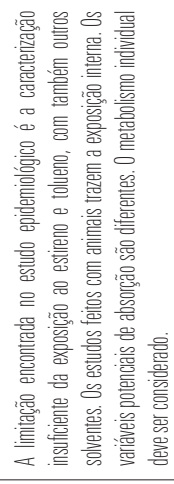 \\
\hline 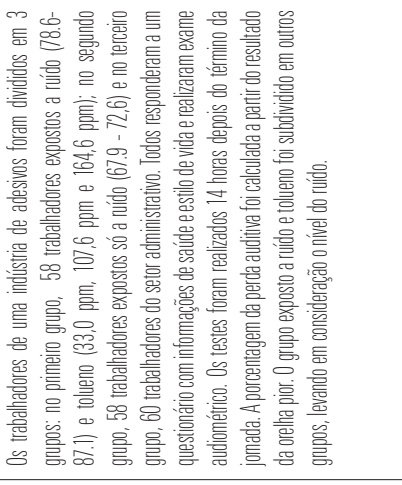 & & 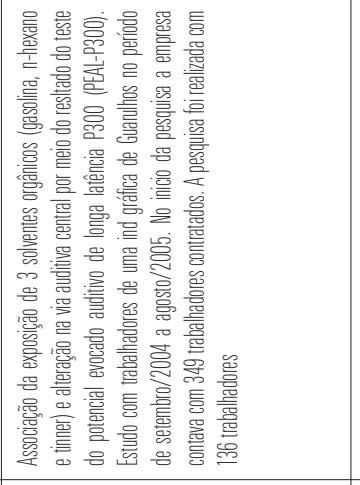 & 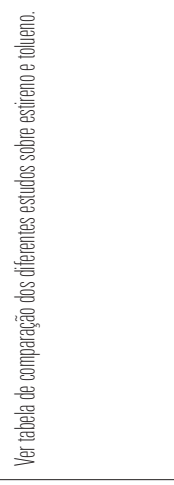 \\
\hline 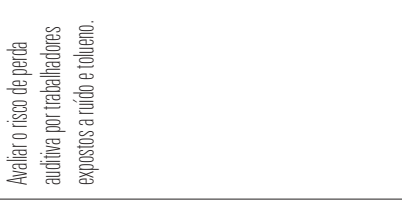 & & 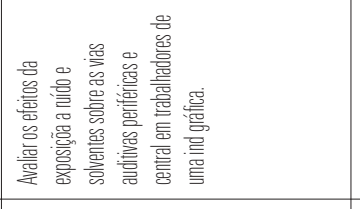 & 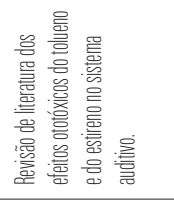 \\
\hline & 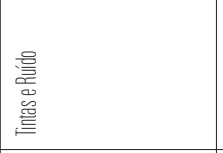 & 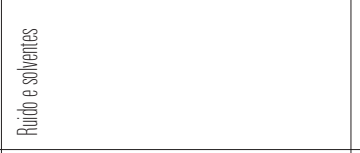 & 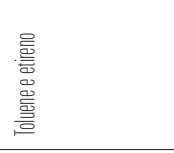 \\
\hline & 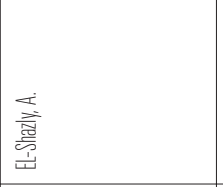 & 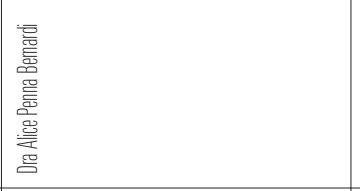 & 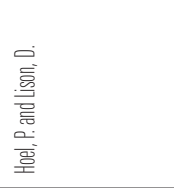 \\
\hline 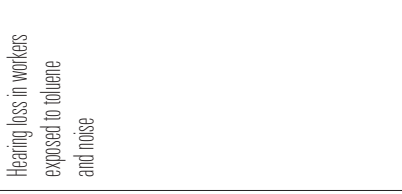 & 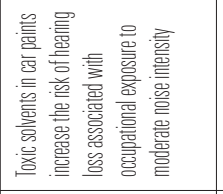 & 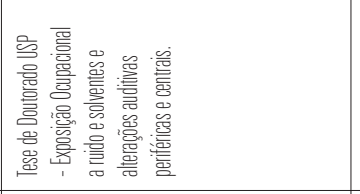 & 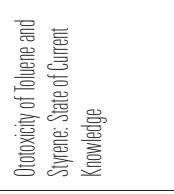 \\
\hline 总 & 吕 & 咅 & 总 \\
\hline
\end{tabular}




\section{REFERÊNCIAS BIBLIOGRÁFICAS}

1. Lacerda A, Leroux T, Morata T. Efeitos ototóxicos da exposição ao monóxido de carbono: uma revisão. Pró-Fono Revista de Atualização Científica. 2005, 17(3):403-12.

2. Steffen V. Ambiente de trabalho: um local de risco. First Pan-American/Iberian Meeting on Acoustics. 2002.

3. Sullivan JB, Vanert M. Alkybenzene solvents and aromatic compounds. In: SullivanJB, Krieger GR. Hazardous materials toxicology clinical principles of environmental health. Baltimore: 1992.

4. Beving H, Tornling G, Olsson P. Increased erythrocyte volume in car repair painters and car mechanics. $\mathrm{Br} \mathrm{J}$ Ind Med. 1999, 48:499-501.

5. Buzio L, Tondel M, De Palma G, Buzio C, Franchini I, Mutti A, Axelson O. Occupational risk factors for renal cell cancer: An Italian case-control study. Med Lav. 2002, 93:303-09.

6. Moen BE, Hollund BE. Exposure to organic solvents among car painters in Bergen, Norway. Ann Occu Hyg. 2000, 44:185189.

7. Baelum J, Andersen I, Millhave L. Acute and subacute symptoms among workers in the printing industry. Br J Ind Med. 1982, 39:70-75.

8. Wang JD, Chen JD Acute and chronic neurological symptoms among paint workers exposed to mixtures of organic solvents. Environ Res. 1993, 61:107-16.

9. CranmerJM, Goldenberg M. Proceedings of the workshop on neurobehavioral effects of solvents. NeuroToxicology. 1986, 7(3):45-54.

10. Santos Junior EA, Buschinelli JTP, Della Rosa HV, Salgado PET, Colacioppo S, Mendes R. Condições de Risco de Natureza Química. In: Mendes Patologia do trabalho. Rio de Janeiro: Atheneu; 2003, p. 325-514.

11. Oga S. Fundamentos de Toxicologia. $2^{\circ}$ edição. São Paulo: Atheneu; 2003.

12. Morata TC, Nylén PR, Johnson AC, Dunn DE. Auditory and vestibular functions after single or combined exposure to toluene: a review. Archives of Toxicology. 1995, 69:41343.

13. NIOSH (National Institute for Occupational Safety and Health). Hearing loss research at NIOSH: Reviews of research programs of the National Institute for Occupational Safety and Health. National Academies Press, Washington, DC, 2006.

14. Eu. Directive 2003/10/EC of the European Parliament and of the Council of 6 February 2003 on the minimum health and safety requirements regarding the exposure of workers to the risks arising from physical agents (noise). Official Journal L 042, 2003.

15. GAGNAIRE F, LANGLAIS C. Relative ototoxicity of 21 aromatic solvents. Arch Toxicol. 2005, 79(6):346-354.

16. Morata TC. Epidemiological study of the effects of exposure to noise and and organic solvents on workers hearing and balance. Cincinnati, University of Cincinnati, 1990 .

17. Morata TC, Dunn DE, Kretschmer LW, Lemasters GK, Keith RW. Effects of occupational exposure to organic solvents and noise on hearing. Scand. J. Work Environ Health. 1993, 19(4):245-54.

18. Abbate C, Giorgianni C, Munao F, Brecciaroli R. Neurotoxicity induced by exposure to toluene. An electrophysiologic study. Int. Arch. Occup. Environ. Health. 1993, 64(6):389-392.

19. Souza MT. Efeitos auditivos provocados pela interação entre ruído e solventes - uma abordagem preventiva em audiologia voltada à saúde do trabalhador. São Paulo, 1994. (Tese de Mestrado - Pontifícia Universidade Católica de São Paulo).

20. Rebert CS, Schwartz RW, Svendsgaard DJ, Pryor GT, Boyes WK. Combined effects of paired solvents on the rat's auditory system. Toxicology. 1995, 105(2-3):345-354.

21. Nylen P, Hagman M, Johnson AC. Function of the auditory system, the visual system, and peripheral nerve and longterm combined exposure to toluene and ethanol in rats. Pharmacol. Toxicol. 1995, 76(2):107-111.

22. Campo P, Lataye R, Cossec B, Placidi V. Toluene induced hearing loss: a mid-frequency location of the cochlearlesions. Neurotoxicol. Teratol. 1996, 19(2):129-140.

23. Lataye R, Campo P. Combined effects of a simultaneous exposure to noise and toluene on hearing function. Neurotoxicol. Teratol. 1997, 19(5):373-382.

24. Morata TC, Dunn DE, Sieber WK. Perda auditiva e a exposição ocupacional a agentes ototóxicos. In: Nudelmann AA, Costa EA, Seligman J, Ibañez RN. PAIR: perda auditiva induzida por ruído. Porto Alegre: Bagaggem Comunicação; 1997. 
25. Campo P, Lataye RE, Loquet G. Toluene and Styreneinduced hearing loss: a comparative study. In : Cochlear pharmacology and noise trauma. London: Noise Research Network Publications. 1998, p. 113-128.

26. Lataye R, Campo P, Loquet G. Toluene ototoxicity in rats: assessment of the frequency of hearing deficit by electrocochleography. Neurotoxicol. Teratol. 1999, 21(3):267-276.

27. Bernardi APA. Trabalhadores expostos simultaneamente a ruído e tolueno: estudo das emissões otoacústicas evocadas transitórias e efeito de supressão.São Paulo: Faculdade de Saúde Pública, Universidade de São Paulo; 2000.

28. Morioka I, Miyai N, Yamamoto H, Miyashita K. Evaluation of combined effect of organic solvents and noise by the upper limit of hearing. Ind. Health. 2000, 38(2):252-257.

29. Fuente A, Mcpherson B, Munoz V, Pablo EJ. Assessment of central auditory processing in a group of workers exposed to solvents. Acta Otolaryngol. 2006, 126(11):1188-1194.

30. Chang SJ, Chen CJ, Lien CH, Sung FC. Hearing loss in workers exposed to toluene and noise. Environ. Health Perspect. 2006, 114(8):1283-1286.

31. EL-SHAZLY, A. Toxic solvents in car paints increase the risk of hearing loss associated with occupational exposure to moderate noise intensity. B-ENT, 2006, 2(1):1-5.

32. Bernardi APA. Exposição Ocupacional a Ruído e Solventes e Alterações Auditivas Periféricas e Centrais. São Paulo, 2007. (Tese de Doutorado - Faculdade de Saúde Pública, Universidade de São Paulo).

33. Campo P, Loquet G, Blachere V, Roure M. Toluene and styrene intoxication route in the rat cochlea. Neurotoxicol. Teratol. 1999, 21(4):427-434. 